\title{
Redesigning Prison: the Architecture and Ethics of Rehabilitation
}

\author{
Roland Karthaus and Lucy Block, Matter Architecture
}

\section{Introduction}

At the time of writing, the prison service is undergoing a period of significant reform. The debate around the purpose of prison is shifting, with a greater emphasis on enabling rehabilitation and reducing recidivism. In the context of austerity and rising demands in core public services, consensus is emerging around the benefits of engaging service users and the public. ${ }^{1}$ A significant reduction in staffing numbers since 2010 has resulted in deep frustration amongst prisoners and staff, and major disturbances in several prisons have occurred against the gradually worsening backdrop of self-harm and individual cases of violence. This raises practical, economic and ethical issues together, and it is our contention that architecture has a key role to play in the performance of prisons in this context.

It is argued that sustainable, rehabilitative behaviour change is dependent upon an individual's decision not to reoffend, and the incentives and support that help maintain that choice are key. Although architecture alone cannot directly change behaviours, our hypothesis is that the design of the built environment does affect behaviour and can support positive change. Recent studies on improving prison architecture have tended to propose alternative, radical models, often informed by exemplary case studies from around the world. ${ }^{2}$ In contrast, the approach of the work covered in this paper has been to engage proactively in existing practices for the commissioning, design, management, and operation of the UK Prison Estate, with the intention of influencing and informing these in a positive direction, through practical and realistic measures.

Since 2011, Karthaus has been undertaking research-based activity to improve the environment of prisons for the people and communities they serve. Spanning two major projects, RSA Transitions; Building a Rehabilitative Culture ${ }^{3}$ and Wellbeing in Prison Design: A Design Guide, ${ }^{4}$ the work has developed an evidence-base and practical proposals for design measures to support health and wellbeing, improving reoffending rates and putting state assets of both land and buildings to more effective use. 

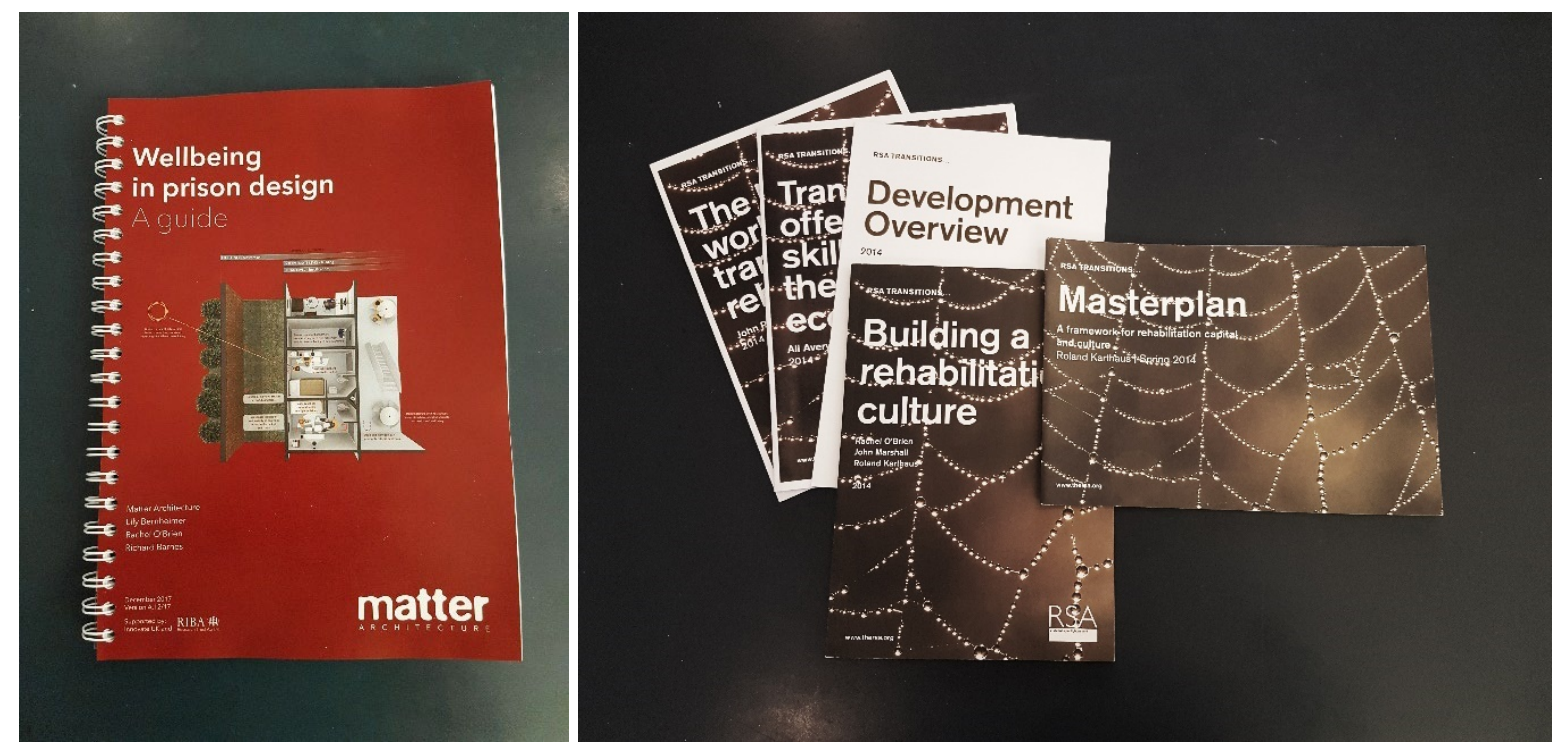

Fig. I - Reports of the two major projects, copyright Matter Architecture

In 2011, RSA Transitions led by O'Brien, with Karthaus and Marshall, was commissioned by the RSA. The project argued that prisons will be unable to successfully rehabilitate offenders unless they are supported to develop stronger, more positive links with local communities and economies. Working on-site with HMP Humber, a pilot feasibility study was developed to repurpose the land and buildings in Ministry of Justice (MoJ) ownership; supporting officers, management and prisoners to implement necessary organisational and cultural change. A Community Interest Company was established to take forward the pilot project locally and a phased masterplan and business plan were developed for implementation and fundraising. A suite of reports was published by the RSA in 2014 covering the various strands of the research, under an overarching policy paper.

Building on this initial project and funded by the RIBA and Innovate UK, a research team led by Karthaus at Matter Architecture, engaged with the Ministry of Justice's Prison Estate Transformation Programme (PETP) in 2017, to provide independent guidance on designrelated benefits within the prison environment and a method for monitoring the success of improvements over time. The guidance uses evidence from the field of environmental psychology to identify areas of design that can support the health and wellbeing of people living, working in and visiting prisons. Touching on planning processes, construction methods, layout, materials, landscape, atmosphere and accessibility, the guidance is informed by direct consultation with prisoners and staff at the UK's newest and largest prison, HMP Berwyn.

In the following sections the purpose of prison and an outline of prison architecture over the past two centuries is briefly considered. In the context of this, the paper discusses the research undertaken through the two major research projects and goes on to consider the wider impact of these projects and the complexity involved in the context of the existing prison procurement process. Much has been written in this field and the context provided 
here is necessarily heavily summarised and simplified. The publications of these two research projects expand on this context in greater detail.

The objectives of the work are to support the current reform agenda for prisons to become places of progress that promote active citizenship and provide conditions that will help people turn their lives around. ${ }^{5}$ This paper contributes to addressing these issues through reflecting on the work concluding in 2017 and considers how it may be further developed and applied.

\section{Purpose of prison}

The prison system has three core objectives: to protect the public; to punish; and to rehabilitate. It is further charged with undertaking all these functions in a humane and transparent manner. ${ }^{6}$ There are those who would like to see a sizeable reduction in the use of prison with an expansion of non-custodial responses and an end to short sentences, ${ }^{7}$ whilst some argue for more frequent use of prison, longer sentences and harsher conditions. ${ }^{8}$

RSA Transitions stated that 'the prison system's role of protecting the public is in part met through giving communities respite for a period of time. But just as the prison population has grown, so has the recognition that too often the system acts as a revolving door; calling into question how successful our current approach is in delivering longer-term public protection and rehabilitation. ${ }^{19}$

The notion of rehabilitation is complex and the role that prison plays is partial. Setting aside wider societal issues such as inequality, prison represents only one part of a Justice service that includes sentencing, probation and other forms of non-custodial punishment. It can be argued that reducing recidivism requires the individual to make positive choices and take responsibility for their actions and the resulting consequences. Furthermore, people in custody need to be provided with a level of dignity, stability and support to make stronger, positive transitions from custody to community.

Since the reduction in prison staff over the past decade however, the role that prison plays in rehabilitation is failing to meet expectations in terms of effectiveness and value for money. ${ }^{10}$ Responses to this have been largely focused on reform of the prison service in terms of its operations, culture and deployment of services. The argument made in the two research projects is that the architecture of the prison estate is also crucially important and that the reform agenda will be thwarted if it is not accompanied by a reform to the way that prison buildings are commissioned, designed, maintained and upgraded. 


\section{Ideological, ethical and architectural history}

An outline of the ideological and architectural history of penal architecture is helpful to understand contemporary prison design, and the existing commissioning process for building prisons. A significant amount of the existing prison estate was built before 1900 and many prisons are arguably not fit for purpose. Prison architecture has a clearly established typology, typically based upon a radial layout with inmates accommodated in wings around a central observation area. This section briefly outlines the ideology behind the established architectural form of prisons and design innovations that are challenging this model. A more comprehensive overview is provided in the Handbook on Prisons. ${ }^{11}$

\section{Georgian and Victorian prisons}

The $18^{\text {th }}$ and $19^{\text {th }}$ centuries saw an evolution in the configuration of prison design, responding to basic health concerns in a similar trend to housing, hospitals and so on, but especially influenced by the social reformer John Howard. At the same time, the exterior architecture of gaols, aimed to project an image of the state as arbiter of justice and of the austerity and severity of being sent to prison.

\section{The Panoptican}

An early influential model was Bentham's Panopticon, ${ }^{12}$ a design for a prison where cells are organised centripetally in a rotunda, maximising surveillance from a central observation point. Designed in such a way that prisoners did not know when and if they were being observed, the continual sense of surveillance was intended to motivate them to regulate their own behaviour, effectively acting as agents of their own control.

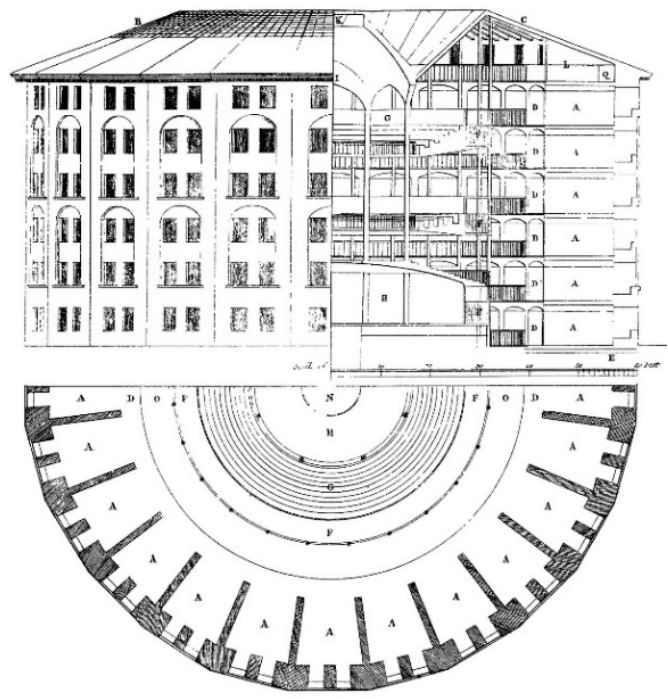

Fig. II - Bentham's Panopticon, part-plan/elevation/section by Willey Revely, 1791 
French philosopher, Michel Foucault considered the psychological manipulation inherent in the Panoptican, addressing the relationship between power and knowledge, and how these impose social control through societal institutions. ${ }^{13}$ This is relevant in both a negative sense via the psychological removal of autonomy from the prisoner; and the potentially more positive sense of architecture's ability to affect psychology through its configuration.

\section{$20^{\text {th }}$ Century development}

The number of prisons expanded significantly in the $20^{\text {th }}$ century, often in repurposed military facilities, as part of a general shift 'out of sight' from urban centres into the countryside. Postwar, there was also an emergence of a more civic architectural language akin to town halls, libraries and school buildings, to create 'palaces of justice. ${ }^{14}$

The early 1970s saw an almost total standstill on new prison architecture, resulting in chronic overcrowding, numerous strikes and violence causing increasing tension. During the 1980s, under the Prison Design Board, new design principles were introduced, including a template and a set of standards for prison design. Some more experimental layout models were built during this period.

Commissioning of new prisons was further expanded in the 1990s through the Private Finance Initiative (PFI) in which operators take responsible for the design, construction, management, and financing (DCMF). PFI changed the approach to prison design, by requiring economic and more narrowly functional parameters, resulting in the 'stripping away' of architectural objectives. Seen as the logical conclusion of the 'hiding away' of prisons from public sight begun in the $20^{\text {th }}$ century, the non-architecture of modern prisons has been termed 'non-places for non-people' and likened to the pure logistical concerns of an 'amazon warehouse', with associated dehumanising effects. ${ }^{15}$

In 2007, plans were announced for three new 'Titan' prisons, that would each house 2,500. ${ }^{16}$ The intention of these new prisons was to reduce pressure on existing assets and enable the 'closures of old, inefficient, and ineffective prisons offering better value for money and much improved chances of reducing reoffending and crime. ${ }^{\prime 17}$ Although these plans have since been scaled back, the MoJ's Prison Estate Transformation Programme (PETP) is currently commissioning new larger prisons to replace existing establishments.

According to their project managers, 'PETP are simplifying the organisation of the prison estate into three key functions: reception, training and resettlement. By investing in and reorganising our estate they will ensure that each prisoner is held in the right place, at the right time in their journey, and the prison population as a whole can be effectively managed.' ${ }^{18}$

Whilst this statement confirms the resettlement function of prison, it also illustrates the overriding logistical concern, which has become more pressing as the prison population grows to capacity. ${ }^{19}$ 


\section{Alternative models}

It is against this backdrop that alternative models have been developed, considering more innovative approaches to reduce the number of people reoffending through an improved prison environment.

In 2009 an interdisciplinary team led by Hilary Cottam with Buschow Henley, published Learning Works, ${ }^{20}$ a '21st Century Prison' model moving away from architecture predicated on imposing power, focusing instead on education. This model was structured around a series of 'houses', arranged as live-work accommodation with the purpose of freeing up time, resources and management involved with the movement of inmates around the prison. The buildings are arranged in a chequerboard layout to maximise social interaction, as well as enhance environmental conditions such as natural daylight, ventilation and views.

The model inverts the logic of Bentham's Panopticon, challenging the prison typology that confines individuals deep within the prison and a regime based on reflection and purposelessness. Although this model presents an innovative approach, it does not integrate readily with the existing operations of the prison service. It is intentionally radical, but as such cannot easily be partially, nor gradually implemented.

In March 2008, the Prison Learning Network ${ }^{21}$ was launched by the RSA, to explore and champion innovative initiatives that were already taking place across the prison estate. It is important to note that whilst strategic, political debates continue about the direction of the prison service, a great deal of grass-roots innovation has taken place led by innovative Governors, officers and ex-prisoners, in some cases supported by philanthropic organisations, charities and social enterprises, most famously the Clink training restaurants. ${ }^{22}$

From this work, the RSA published The Learning Prisons Report, ${ }^{23}$ which suggested key principles for reform 'seeing prisons as a core public service that ... begins to reimagine how prison's role as educator could be placed centre stage to issues of public safety. ${ }^{24}$ Although the study touched on similar themes to Learning Works, in terms of the focus upon education as a means of rehabilitation it was more engaged in the day-to-day operation of prisons, directly looking at case studies to ground the theoretical work in reality. It is within the context of this pragmatic approach to change that the RSA Transitions and Wellbeing in Prison Design projects were established, attempting to match policy measures with complementary architectural and design proposals, following a period in which architecture was largely forgotten or dismissed in addressing the challenges of the prison service.

\section{Conclusions}

Throughout the evolution of prison design, themes central to environmental psychology are evident but not explicit. As 'total institutions' ${ }^{25}$ the social and psychological role of prison architecture is more apparent than in most other situations. Whilst power and control are assumed requirements for the security of both the inmates and officers, a more progressive question arises from this; can prison architecture be designed to support prisoners to rehabilitative ends? 
Despite progressive shifts in attitude regarding the purpose of prison, little has fundamentally changed in terms of how prisons are designed and built, and modest architectural development has been stifled by procurement. Recently, broader political consensus on prisons as places of rehabilitation has developed; for improvements to be made both social and economic costs, need to be accounted for. ${ }^{26}$

The Learning Prisons Report observes that, 'without compelling evidence of impact on reoffending rates, it is hard to see how we can [develop] a more reasoned public conversation about prisons as a core public service... unless we can convince the public of prisons' potential for giving people the second chance most of us believe in, and that this is consistent with public safety, it will be harder to generate the wider community participation and local partnerships suggested here. ${ }^{27}$

What is clear is that in order for a more innovative approach to be adopted there must be a level of buy-in from both public and political agencies, and a need to demonstrate the feasibility and benefit of such schemes.

\section{RSA Transitions}

In 2011, the RSA Transitions team, led by O'Brien with Karthaus and others, was commissioned to produce a policy paper, feasibility study and research-in-action project, to establish a new social enterprise model for rehabilitation and resettlement around prisons, culminating in a suite of documents entitled RSA Transitions; Building a Rehabilitative Culture. ${ }^{28}$

\section{'Opening up' the prison to its context}

There is extensive and mounting evidence that suggests that our connections to other people, the nature of these relationships, and extent to which we have support networks significantly influence our behaviour, life chances and wellbeing. ${ }^{29}$ Despite this, these insights are generally not reflected in the way we design and run core public services, practical interventions and policies.

The project suggested that, 'unused land and buildings owned by the Ministry of Justice surrounding prisons, could provide a space for unlocking social potential within prisons and the wider community [and] help prisoners inside make the transition from offender to active citizen, and ... embed the prison in the local community; enabling local employers and 'through the gate' services to strengthen not just the chances of reducing reoffending but also a broader culture of rehabilitation?'30

Several relevant case studies were considered, including The Clink at HMP Highdown. ${ }^{31}$ The Clink restaurant was opened in 2009 , with a view to provide formal training, qualifications 
and support for prisoners in finding a job after release. In addition to the restaurant itself, the produce is supplied directly from the restaurant garden in the prison grounds, with the aim of making the business self-sustaining. The restaurant is staffed by prisoners; preparing and serving meals to prison staff and invited members of the public. The incentive offers prisoners access to work experience within an operational business, opportunities to gain catering qualifications, and connections to a full-time job on release.

Whilst the case studies demonstrated individual initiatives, it was evident that there was no overriding national strategy, with each example appearing as a one-off or ad-hoc. The viability and success of the case studies could therefore only be based on individual circumstances, with unique signifiers of success or failure.

\section{Co-design process}

RSA Transitions proposed a social enterprise model to address this issue. Its form and functions were developed through a series of roundtable discussions and seminars with specialists in the criminal justice system, RSA Fellows, staff, former prisoners and prison governors. Participation was crucial to the outcomes of the study, and through continual consultation and feedback, the model was the product of a creative and instructive co-design process. The team engaged and consulted with hundreds of individuals and organisations; including workshops inside and outside of prison.

Workshops took place in Summer 2013 with prisoners, staff and ex-offenders. Participants were asked to identify priorities that they felt were most important to ensuring that prisoners did not reoffend; what can be referred to as 'rehabilitation capital.' ${ }^{32}$ The feedback helped to clarify constraints and opportunities and raised new ideas. Particularly in relation to existing services required within the prison that could be enabled by RSA Transitions; providing revenue income, training and employment opportunities. The engagement process was intended as a demonstration of developing a network that could support the project through its conception and implementation. The range of consultation undertaken was integral to engaging local businesses, employers, local and regional agencies, as well as gaining public support for the scheme.

\section{Pilot Project}

A pilot project was developed in partnership with HMP Humber in the East Riding of Yorkshire and focused on the physical architectural setting, situated outside the prison walls, alongside organisational and cultural change within the prison. A masterplan was developed for the location of buildings to accommodate the various activities highlighted through the co-design process. The site was conceived as a location where a combination of support services, training, employment opportunities and community facilities could be brought together in a wider landscape environment, acting as a broader resource for rehabilitation. The contention here was that bringing these activities together could establish a network of 
support, social engagement and paths to employment that can underpin the concept of rehabilitation capital and culture.

Over two years working on site with HMP Humber's management team and staff, a proof of concept scheme was drawn up to repurpose the land and buildings. The site and its neighbouring communities offered a specific set of opportunities and constraints, helping to bed the proposal into its context. At the same time, the process of developing the pilot was set out in the reports to act as illustrative guidance for other, different sites.

The focus for the physical development of the site centred on the existing farmstead and manor house complex. ${ }^{33}$ Everthorpe Hall had been empty for several years and was in a poor state of repair. The site provided existing buildings that could be converted and redeveloped to accommodate varying activities, without detrimental impact on the wider landscape or the residential community. Working with the HMP Humber workshops and training team and providers, the Transitions team explored the renovation of Everthorpe Hall as a case-study, with training and skills development for offenders, identified as a testing ground and capacity building opportunity.
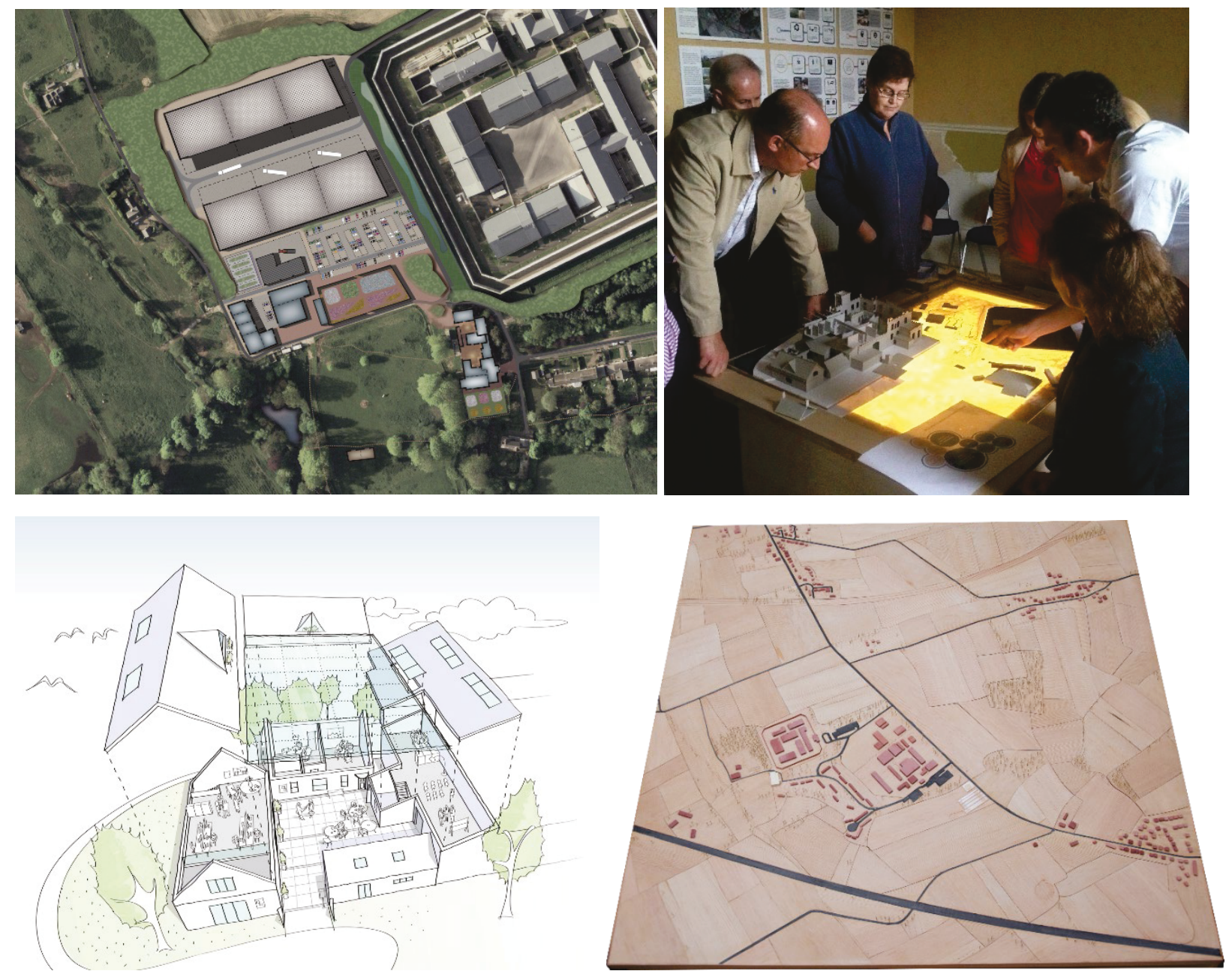

Fig. III - Images from the HMP Humber pilot project, copyright Matter Architecture 


\section{Project conclusions}

The main conclusion of the study was 'that prisons alone cannot succeed in the task they are being asked to undertake; principally to increase the number of people leaving who will desist from crime and resettle. ${ }^{34}$ RSA Transitions argued that rehabilitation 'requires us to embed prisons in their communities and economies, and that more of ' 'us' - the public, employers, entrepreneurs and wider support services - need to play their part.' ${ }^{35}$ The report focused on building and assessing individual 'rehabilitation capital' and institutional rehabilitation culture to provide an effective practical demonstration and lend itself to wider systemic integration.

The teams' objective for Transitions was to develop the idea in practice on site, to become an evaluated pilot that could demonstrate value for money, reduce reoffending and strengthen rehabilitation culture within prisons and their communities. Ultimately the goal was to demonstrate that such a model could be feasible, sustainable and replicable. A Community Interest Company, Transitions Spaces CIC was established with O'Brien and Karthaus, and other stakeholder representatives as Directors. Discussions were held with MoJ estates to explore an asset transfer, but ultimately these were inconclusive. The approach of the team was that of engaged application: researching potential through testing and piloting. A similar approach was taken in the second major project; Wellbeing in Prison Design.

\section{Wellbeing in Prison Design}

In 2017, supported by the RIBA and Innovate UK, Karthaus led a multi-disciplinary team to produce a research-based design guide to improve prison environments, focused on supporting health and wellbeing through the prioritisation of design measures in the prison environment. Research was conducted over a 6-month period, alongside the MoJ team responsible for commissioning new prison buildings under the Prison Estate Transformation Programme (PETP).

Evolving from broader research into the principles of prison design, supported by the RIBA Research Trust, and building upon the outcomes of RSA Transitions, the Wellbeing in Prison Design research project was part of a wider, ongoing review of the role of physical assets within the prison reform agenda. Wellbeing in Prison Design sought to improve the environment of prisons for all users, through informing architectural design with the overall objective of supporting rehabilitation and reducing reoffending. ${ }^{36}$

The project was developed in parallel with the MoJ Prison Estate Transformation Programme's (PETP) current procurement process to provide the opportunity for PETP to test and refine the guidance through application, and to monitor and report on the benefits arising from design measures. ${ }^{37}$ The PETP team shared their design development and plans for delivery of rehabilitation benefits through the new prisons construction programme. These circumstances provided a unique opportunity to engage with a live process in which meaningful change could be implemented. Accordingly, the design guide focused on areas 
identified as priorities and was cross-referenced with the MoJ specification documents so that it could be incorporated into employer's requirements for new prison design. An electronic user-survey, piloted in HMP Berwyn, was intended as a long-term, continual generator of new evidence for improvements in prison design.

The Wellbeing in Prison Design report was organised as a set of semi-independent documents, or chapters, to anticipate a wide range of interested audiences. A chain of evidence was drawn through the chapters, so that the bases for design improvements were explicit and could be updated over time. The following sections describe in outline each of the chapters.
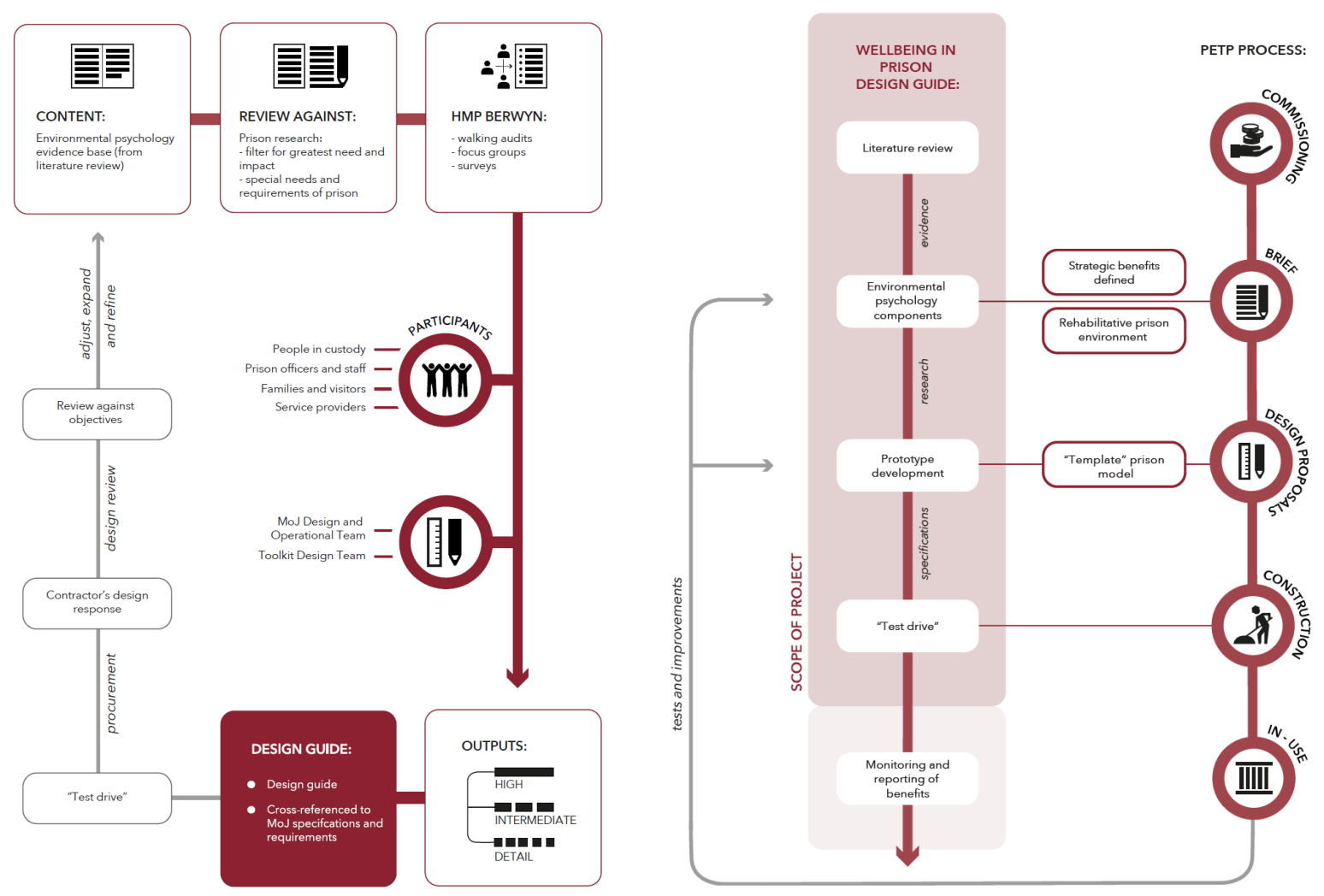

Fig. IV - Process diagrams showing method and context of the project, copyright Matter Architecture

\section{Chapter 1: Policy context}

This chapter describes the context of the project, the aims, objectives and scope that led to the development of the design guide. In early 2016, the Government recognised that the prison system was in need of radical reform and that people in prison must be understood as assets, not liabilities. Six reform prisons were identified and given a remit to operate more autonomously, with the objective of improving rehabilitation outcomes. ${ }^{38}$ 
The prison population is diverse and for rehabilitation to be effective it can be argued that prison needs to be more responsive to individual needs. ${ }^{39}$ Evidence supports a need for innovative approaches and interventions that can help people develop strong relationships and resources needed for stability.

'A rehabilitation culture or whole prison approach [is based upon the] institutional values, work practices, skill and behaviours needed and emphasises the role that networks and relationships have to play in supporting prisoners journey to active citizenship and desistance from crime. ${ }^{40}$

As acknowledged in the Prison Safety and Reform White Paper published in 2016, architecture has a key role to play in the implementation of that culture: 'we will never be able to address the issue of reoffending if we do not address the current level of violence and safety issues in our prisons... This requires a huge cultural and structural change within our prisons - a transformation away from offender warehouses to disciplined and purposeful centres of reform where all prisoners get a second chance at leading a good life.' ${ }^{41}$

The White Paper suggested a pivotal moment, when the rehabilitative purpose of prison would be strengthened in law, however it was not formalised into statute, falling victim to the political attention diverted to Brexit. Nonetheless, the principles set out in the paper continue to be restated and supported by successive Justice Ministers to date.

\section{Chapter 2: Environmental psychology}

The project drew on knowledge from the field of environmental psychology, to identify environmental characteristics supportive of health and wellbeing. This chapter summarised the literature review and presented the environmental psychology evidence base, which the design recommendations were measured against.

'Prisons are closed, restricted communities... the way they look, feel, are designed and built has enormous impact on those inside. ${ }^{42}$ Prisons are inherently stressful environments and long-term stress has significant, negative effects on people's health and wellbeing. ${ }^{43}$ The combination of specific requirements means that, 'simple, universal measures for reducing stress may not apply in the same way [as other building types].' 44

The wellbeing of all those engaged in the system, including those who work in it, is considered a common factor that if supported through a positive environment will be fundamental to achieving desired change. It is our contention that although the built environment does not determine our behaviour it can strongly influence it. Direct cause and effect are hard to prove, but the study of environmental psychology provides a basis for linking specific characteristics with long-term health and wellbeing. Environmental psychology draws on knowledge and research from diverse disciplines, including psychology, anthropology and neuroscience, to theorise and test how humans respond to their environments. 
Environmental psychology focuses on health and wellbeing, due to physiological changes, triggered by environmental conditions, which is crucial for rehabilitation in two ways. Firstly, support and training programmes that are delivered in prison require a certain level of capability that people who are physically and/or mentally unwell or stressed struggle to achieve. 'A reduction of fear and stress is fundamental to support motivation and the creation of opportunity for a prisoner to become an agent of their own change and practice the skill and develop the relationships that will be essential to a sustainable reduction in reoffending. ${ }^{\prime 45}$

Secondly, resettlement from an institutional setting requires a degree of self-efficacy that presupposes certain levels of wellbeing. As those in prison disproportionately suffer from mental and physical health to begin with, an environment that exacerbates these over the long-term is a strong inhibitor of rehabilitation. In assessing the overall wellbeing of an establishment such as a prison, environmental factors can be understood to impact individual and group wellbeing and behaviour on three different levels: physical; functional and psychological. ${ }^{46}$

'Building design can either support or restrict the process of rehabilitation and can add value to this process by being adaptable, by aiding coherence and by reinforcing positive messages through its symbolism. ${ }^{47}$

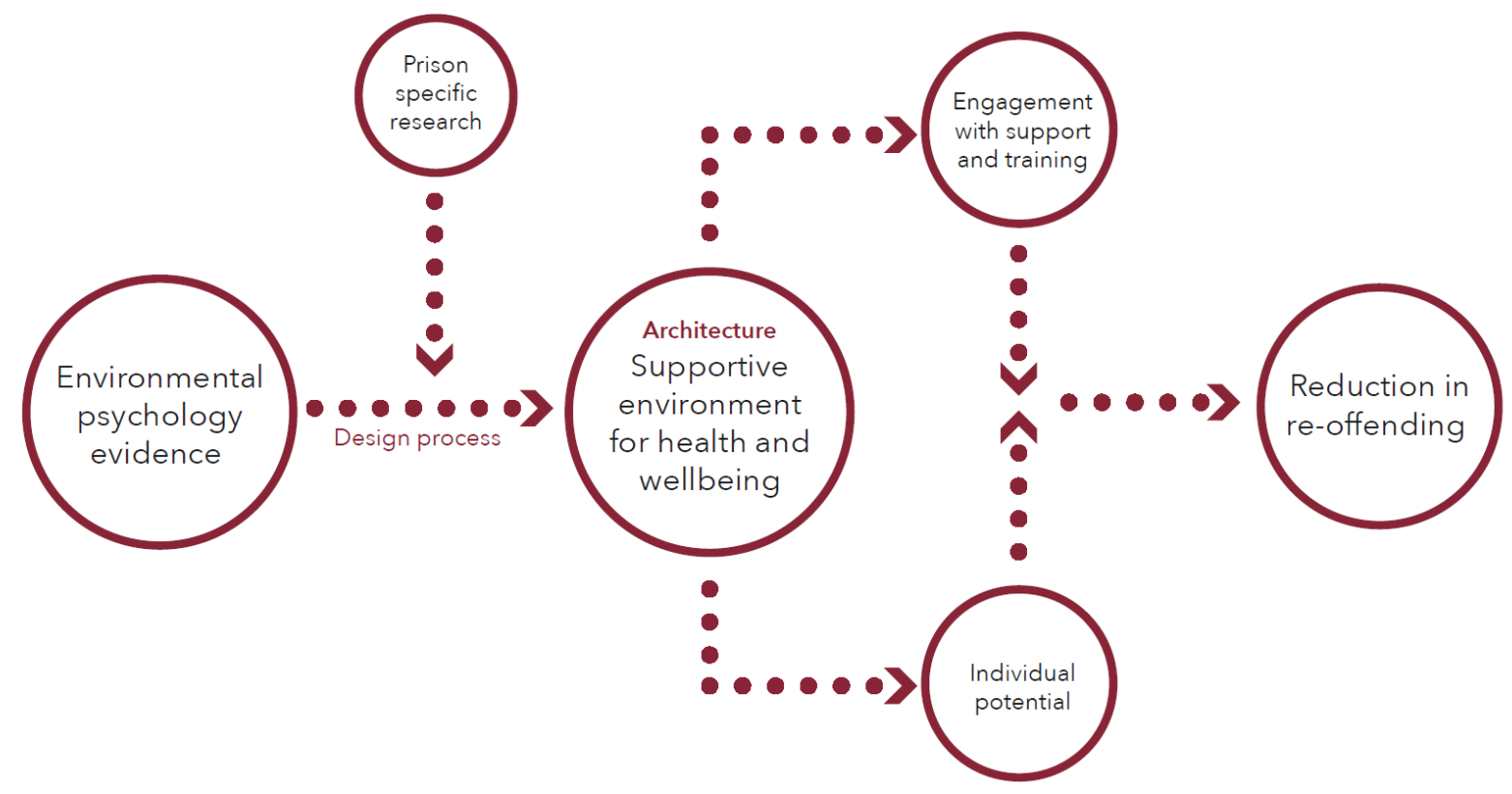

Fig. V - Logic diagram, copyright Matter Architecture 


\section{Chapter 3: Fieldwork}

A responsive design approach, engaging directly with those who use, work in, manage and commission the prison estate, was undertaken to identify the most pertinent areas for intervention. In this chapter, the report summarised the link between health, wellbeing, rehabilitation, and resettlement. The fieldwork was summarised, and some interim conclusions drawn, to inform the design guide.

Fieldwork study visits were made to two recently opened establishments. These visits were considered as case studies, and although not broadly representative of prisons generally, provided insights at a particular moment in the new prison building programme. The aim was not to be directly reactive to specific circumstances encountered, but to sense-check the theoretical work and open the process to the building users, to benefit from their experiences.

\section{HMP Low Moss, Scotland}

In 2017, a visit was made to HMP Low Moss, with representatives of the Scottish Prison Service commissioners, the architects Holmes Miller, and the construction contractor Carillion. An informal visit provided a useful case study in demonstrating the potential for design innovation. The relatively high-quality environments of the exterior of the building, the landscaping, reception, staff facilities, visitors centre, and education block were strikingly different from most other prisons. Whilst in-depth research was not possible in this case, the different philosophy of commissioning and design was apparent. Anecdotally, the relatively small scale of Scotland's devolved prison service facilitated this, meaning that all the decision-makers could meet in a single room and agree to do things differently. The scale of the prison service in England and Wales is many times greater.

\section{HMP Berwyn, Wales}

HMP Berwyn is the UK's largest prison with a capacity of 2,106 , a decision that was widely criticised at the time as detrimental to rehabilitation. ${ }^{48}$ Survey work in the prison was undertaken over three separate visits. In Spring 2017, a visit was made to agree the format of the surveys and view the spaces prior to occupation. Once the prison had been open for a few months and was at approximately $25 \%$ capacity, a follow up visit was undertaken. Structured meetings were held with a selection of staff with different roles, along with escorted 'walking audits' with officers and peer mentors from amongst the men in custody. In addition, some acoustic testing was conducted in an unoccupied house block. Following the fieldwork at HMP Berwyn, a survey was developed for distribution amongst the entire population of the establishment, including staff and men in custody. The survey was designed together with the peer mentors, to be delivered using the 'in-room' technology: laptops given to each man in custody, connected to an internal prison network. 
Originally intended as a medium security 'Category B' prison, HMP Berwyn is operated as a lower risk 'Category $C^{\prime}$ prison, but retains many of the additional physical security measures, including extensive internal fences, gates and bars over windows (including in some staff areas). The plan is similar to many prisons, with radial house blocks and individual facility buildings, within a perimeter wall. Built more densely than is common, the compactness of the site has some advantages for movement and logistics, but neither facilities nor outdoor space appeared to be adequate for the future, full population. The lesson from other prisons is that outside space is often built upon later as ad-hoc expansion of the perimeter wall is more difficult and costly.

HMP Berwyn was striking in that significant efforts had been made to turn a mostly conventional prison into a more inspirational and uplifting environment. Walls were painted brighter than usual and large-scale, high quality prints of landscapes applied to the walls. Positive landscaping of the lawn areas between the buildings was beginning to emerge with flower beds and trees. These physical measures were matched with the operational ideology; with those in custody simply referred to as 'men' and the cells as 'rooms.' The guiding principle was that officers and staff are enablers of rehabilitation primarily. The management regime publicised its desire to put in place a comprehensive approach to rehabilitation through supporting the men in custody to maintain a sense of dignity and identity. ${ }^{49}$
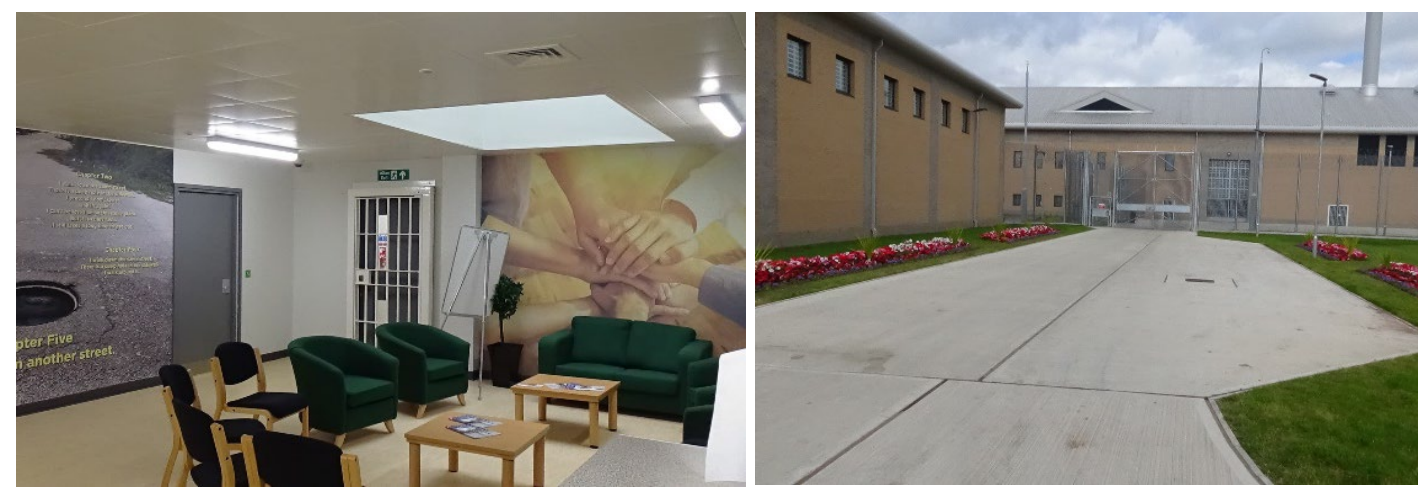

Fig. VI - HMP Berwyn, copyright HMP Berwyn/HMPPS used with permission

A further purpose of the fieldwork was to demonstrate the value of engaging with qualitative post-occupancy evaluation and feedback. The electronic survey provided some tentative primary data to inform the process, with 305 completed surveys received, but the aim was to avoid specific responses and therefore the primary evidence is treated as purely informative 
in the design guide. Over time, it is intended that the survey input can be used to expand the evidence.

Amongst the findings some areas of poor staff welfare provision and issues relating to environmental comfort were evident. The survey identified that an issue for most users of the building was acoustics. Drawing on evidence from the field environmental psychology, the report observes that, 'unpredictable, intermittent and uncontrollable noise ...causes significant stress, with powerful and enduring negative impacts on wellbeing. ${ }^{50}$ Similar issues were encountered in other relatively new facilities and anecdotally reported as problematic.

Whilst the relevance of specific case studies is limited, there are both positive and negative measures that stand out as being particularly pertinent and have informed the focus of the design guidance. In the case of HMP Berwyn, at least some of the shortcomings appear to have arisen because of changes to the originally intended use and security requirements of the building, or from adjustments to the design and specification late in the delivery process. These issues point to a requirement for improvements in commissioning and procurement, as well as in the design itself. 
- Type of room?

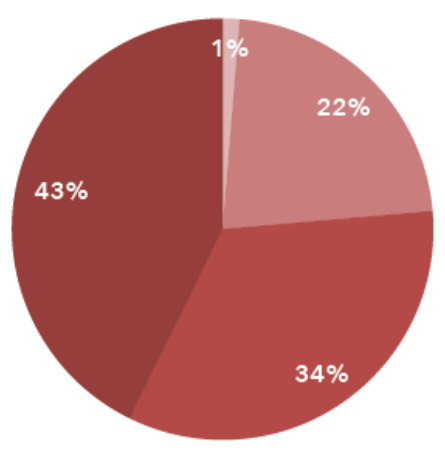

Accessible room

Double and sharing

Double and not sharing

Single

- Best things

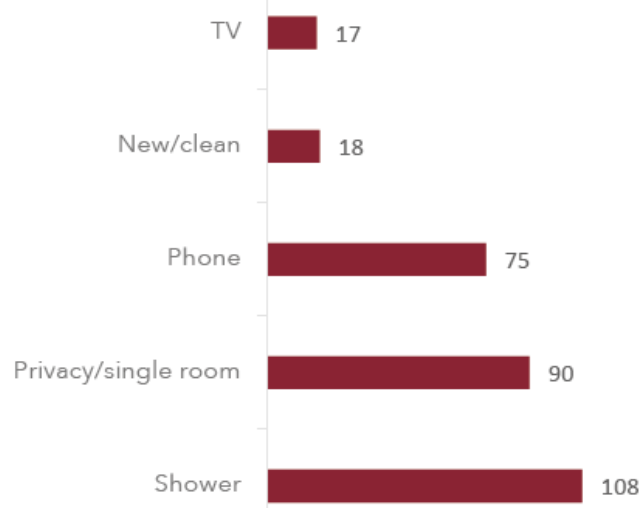

108
- To what extent does your room make you feel...

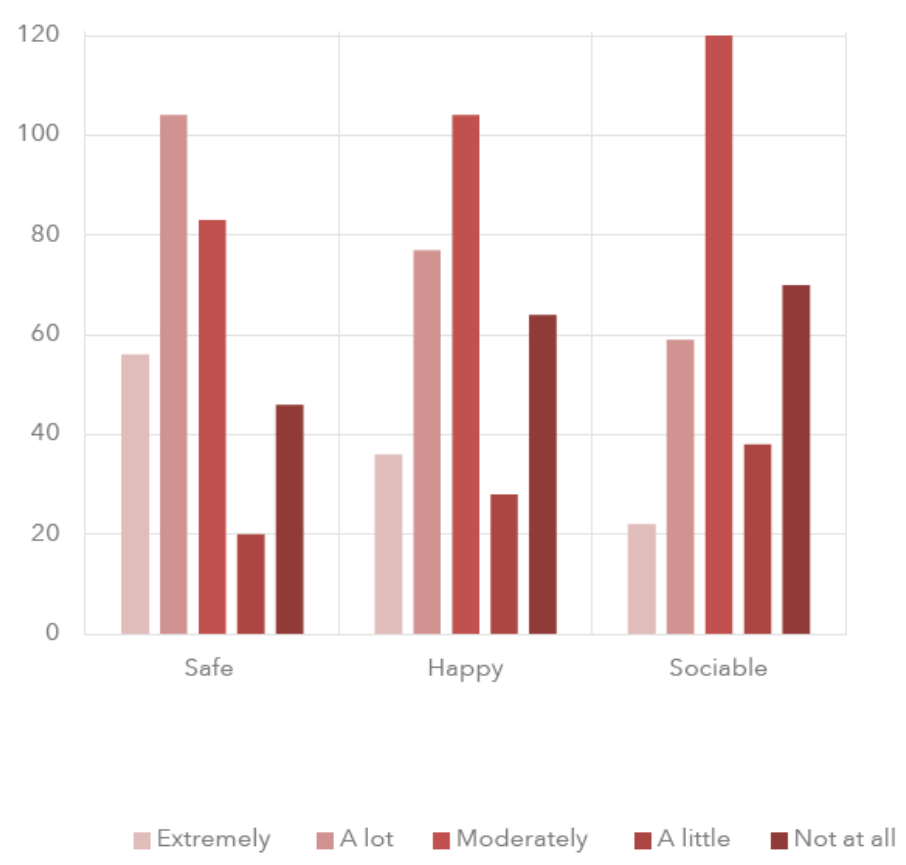

- Worst things

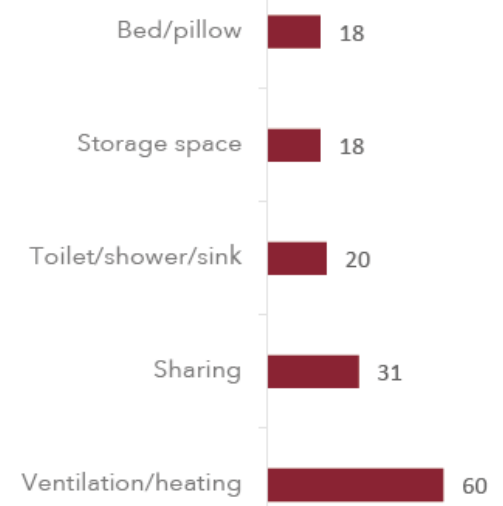

Fig. VII - Extract from HMP Berwyn survey analysis, copyright Matter Architecture 


\section{Chapter 4: Design guidance}

The final chapter set out the initial version of the design guide and was organised as a reference document. Links on each page connected the guidance to the principles established in the environmental psychology evidence base in Chapter 2.

The purpose of the design guide was to give qualitative, supplementary guidance in the design process of prisons, providing key issues for design consideration that could significantly affect the health and wellbeing of all people in the prison environment. The guidance was designed to inform an iterative design process, differing from credit-based scoring systems such as the WELL building standards. ${ }^{51}$ It was intended that the Wellbeing in Prison Design Guide would continue to be refined and expanded through its intended use in the design of new prisons and potential use in existing establishments. The design guide was organised into three tiers: high, medium and detail level.

At the high level, overall objectives outlining the issues affecting the whole prison are organised into three core themes: process; configuration; and design. ${ }^{52}$ Design principles are intended to be the starting point in the planning and site layout process. These are derived from both direct environmental psychology evidences and a broader evidence base of comparable settings. In relation to briefing and planning procedures, the guidance recommends that although new prisons are established centrally by the MoJ, a successful building will respond to local circumstances to maximise opportunities for formal rehabilitation partnerships, as well as more informal relationships with local communities. It reiterates the importance of early engagement to enable potential rehabilitation opportunities to be supported at the strategic level, informing the client brief.

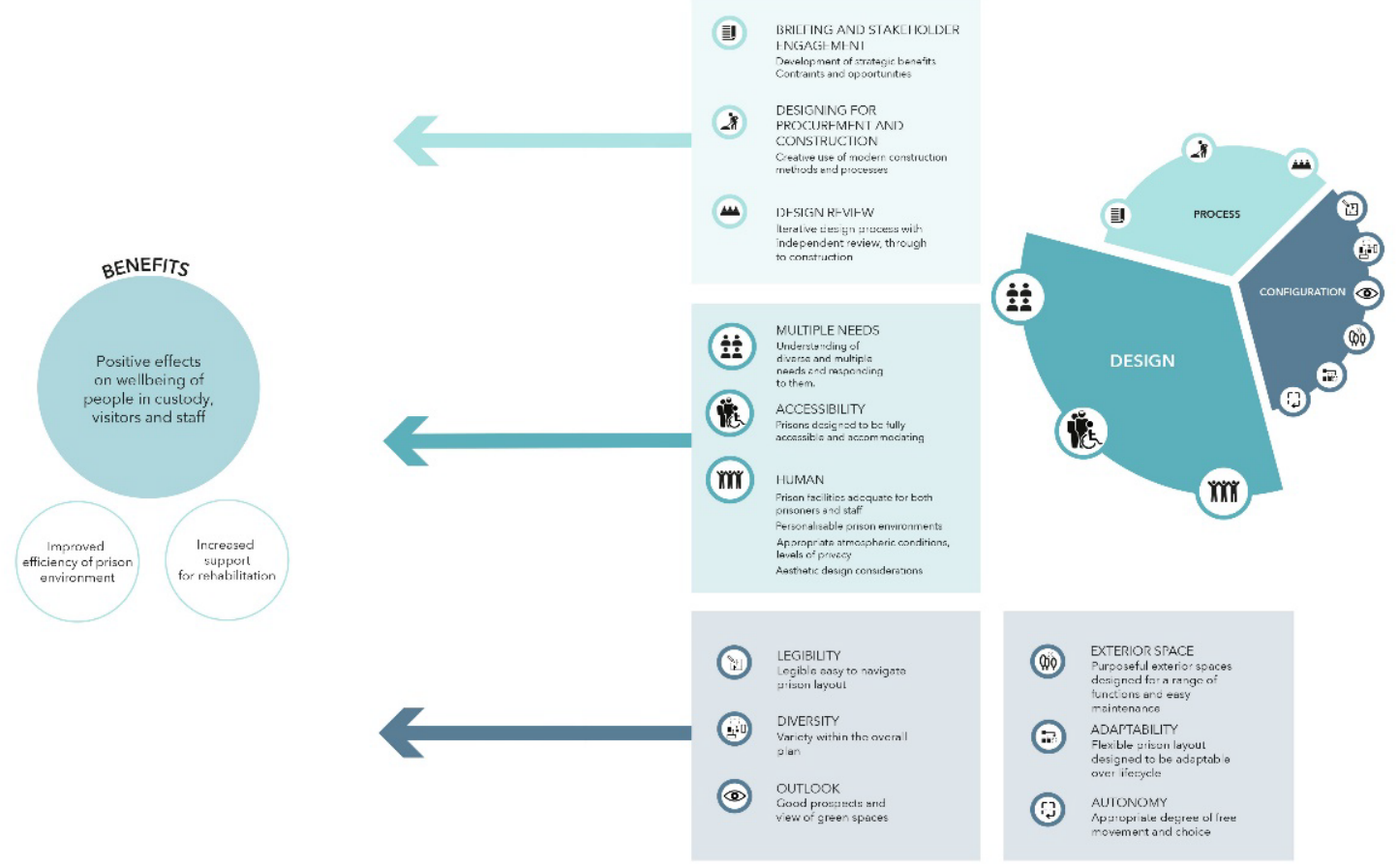

Fig. VIII- Extract from high level guidance of Wellbeing in Prison Design Guide, copyright Matter Architecture 
At the intermediate level, general provisions related to specific buildings and functions in the prison are described, aimed at improving the health and wellbeing within the differing functional environments. ${ }^{53}$ This section highlights specific aspects of the typical building design, such as house blocks, visitor centres and individual cells. Strategic observations relating to relationships, outlook, external spaces, form and layout are described, alongside strategic environmental considerations. Potential design responses are aligned with principles for improvement, related to the environmental psychology evidence base.

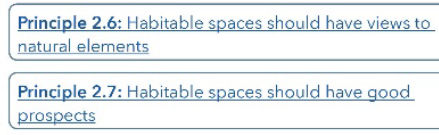

Principle 2.7: Habitable spaces should have good

prospects

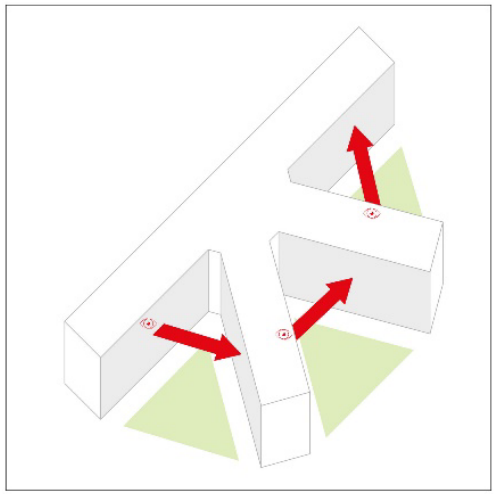

Typical situation

- Cell windows that have limited or no vicws bryond

the exercise yard are

- Windows that do not

provide good prospect

reduces the perceived safety
and heightens the sense of

being trapped

- Cell windows looking into

one another do not allow

adequate privacy

Principle 3.7: Identify, anticipate and accommodate for

Principle 2.13: Prison buildings and masterplans should be adaptable to changing future needs
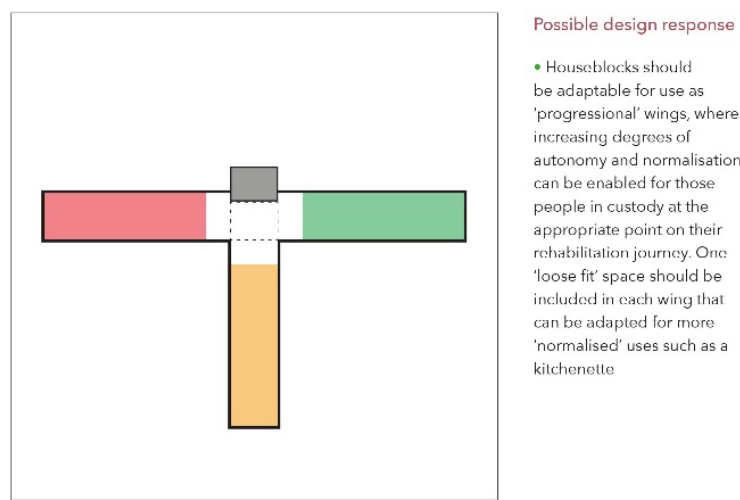

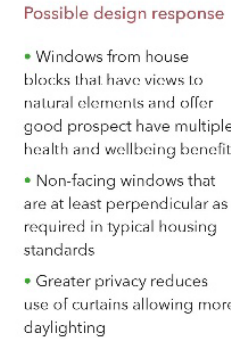

daylighting

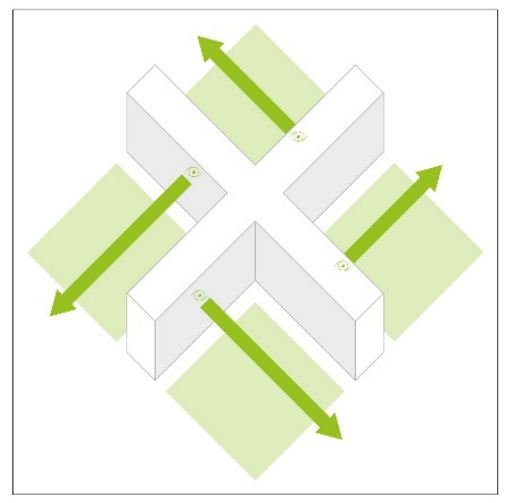

Principle 2.2: Prison designs should incorporate diversity to enable a sense of identity within the institution

Possible design response

- A variety of forms and colours helps to create diverse and interesting environments that increase legibility and give a sense of identity to the built environment. Forms and colours should be carefully chosen to work togesther, whilst avoiding institutional aesthetic.

- Custodial Property Colour design guide (Issuc 01 March 07) provides useful guidance on the effects of colour on spatial legibility - Within a coherent set. individual colours and forms can support identity within a larger institutiona environment

- Colour palettes should be designed carefully to achiev a high aesthetic quality that is not institutional in nature. Many colour palettes are designed by the architect Corbusier

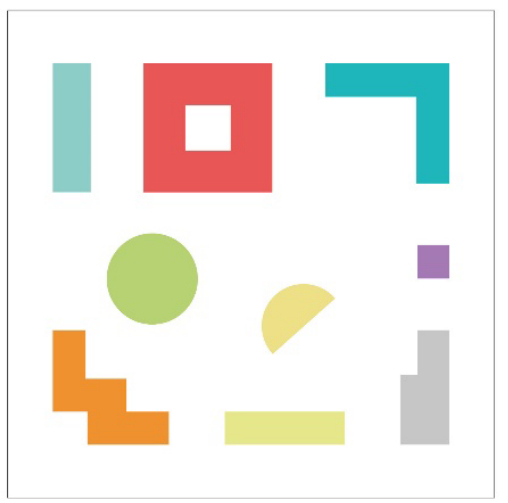

3.4.3 Place factors / Design / Order and complexity

3.4.4 Place factors / Design / Comfort and awe.

Fig.IX - Extracts from intermediate level of Wellbeing in Prison Design Guide, copyright Matter Architecture 
The detail level describes specific opportunities for improved, integrated design issues at a construction level of detail. ${ }^{54}$ Typical details are explored, addressing issues such as acoustics, lighting and ventilation.

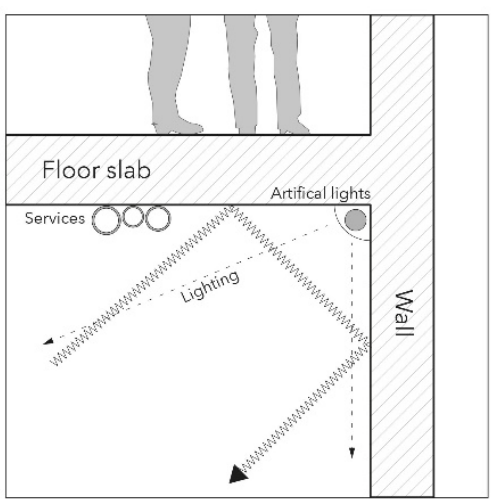

Typical situation

- No acoustic absorption. Live acoustics with long reverberation times hinders communication and encourages shouting. - Direct artificial lighting causes cycstrain and upsel. circadian rhythrns.

- Surface mounted services are not integrated in building design - Hard, 'mean' aesthetic that does not support normalisation.

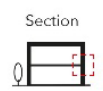

Possible design response

- Integrated design enables many, related issues to be addressed together. Security and maintenanec issuess can be addressed through design and fabrication.

- Opporlunilies Sor Moderr Methods of Construction greatly increase efficiencies and reduce labour on site.
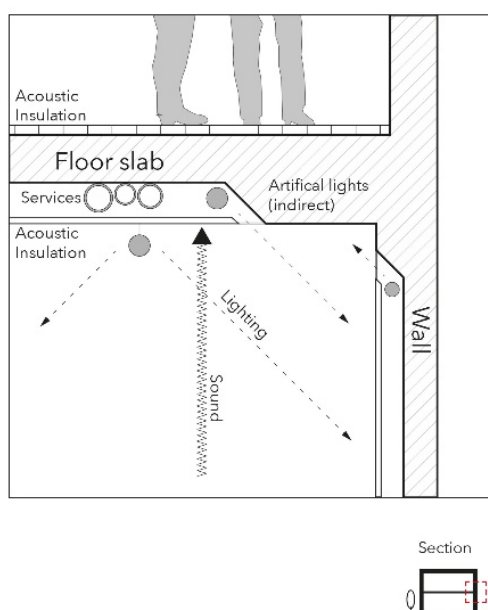

Possible design response - Horizontal ventilators at the ventilation much like Victorian sash windows, providing

- Opportunities for 'bay' - Opportunities for bay wirlows to enable viems a be explored.

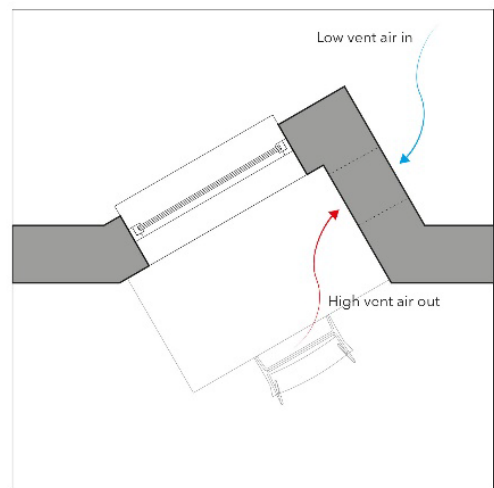

Fig.X - Extracts from detail level of Wellbeing in Prison Design Guide, copyright Matter Architecture

The study established a framework for linking the broader academic evidence with specific design measures in the context of current prison design practice. The aim was to demonstrate the value and effectiveness of people-centred design within a highly constrained building type. 


\section{Wider impact of the research work}

The two applied research projects summarised in this paper were independently commissioned and funded, but shared similar objectives and formed the body of a continuous area of practice-based research concluding in 2017. The latter project drew on knowledge gained through the former and both contributed to a shift in policy and debate around the need for change to support a reduction in reoffending. Parallel work undertaken by O'Brien and others at the RSA for the New Futures Network, a policy platform to support the reform agenda in prisons, has begun to set out pathways to organisational change and provides a link between policy and practice. ${ }^{55}$ Public debate between the need for the justice service to punish and rehabilitate remains as polarised as ever, but the sustained shift in political messaging is clear even during the period of these projects, which saw six successive Justice Ministers.

Speaking recently at the RSA the Rt. Hon. David Gauke set out the Government's view on what prison is for: firstly, the protection of the public; secondly, punishment as a sanction and deterrent; and thirdly, rehabilitation. In the remainder of his speech, he underlined the priority of the first two purposes before moving on to the third, as his predecessors have consistently done since Ken Clarke in 2010. He acknowledged that some prisons do not achieve this but failed to acknowledge the inherent tensions between these distinct objectives. ${ }^{56}$

Whilst the research work covered in this paper has contributed to and supported what is a significant shift in policy emphasis, there is clearly still further progress to be made in rebalancing these priorities as reoffending rates remain stubbornly high. ${ }^{57}$ Without having the space to explore fully in this paper, prisoner risk categories are key. ${ }^{58}$ There are clearly many dangerous people in prison from whom the public need to be protected, but there are many more who pose relatively little danger, whose punishment costs the taxpayer vast amounts of money and have high reoffending rates on release. Fundamentally, the prison system still appears to prioritise the requirements of the former minority over those of the latter majority. ${ }^{59}$

There seem to be two key challenges here; financial and ethical. The prison system as currently organised makes little financial sense. The disproportionate cost of reoffending, ${ }^{60}$ even while conditions in prison are at best highly unpleasant and at worst apparently unbearable, clearly demonstrates that prison does not properly act as a deterrent nor encourage rehabilitation. Meanwhile its effectiveness in protecting the public is extraordinarily high; over the past 6 years, between 9 and 13 'escapes' per year have occurred out of a prison population of more than 80,000 i.e. $0.0125 \% .{ }^{61}$ One high-risk escape is a serious occurrence, however the financial balance of security per person versus the cost of reoffending and rehabilitation on release is not one that stands logical scrutiny. ${ }^{62}$

This is the point at which the financial challenge blurs into an ethical one. As a society, we have persistently tolerated the vast financial cost of protecting the public from a minority of offenders, largely because we cannot reasonably quantify the cost of a major security breach that results in one or more deaths. The costs of reoffending are dispersed widely and are not 
so easily apportioned, but anyone involved in the justice sector is acutely aware of the large numbers of offenders and their families' lives that are permanently, seriously damaged through the experience of prison. Such permanent, continual punishment is explicitly not a purpose of prison and is clearly at odds with its stated purpose of rehabilitation.

This concept of rehabilitation also contains an ethical quandary. Much of the theory underpinning it asserts that individuals have made incorrect or 'bad' choices, resulting in law breaking and that those individuals require corrective action to be imposed upon them to change their decision-making and learn to assume responsibilities. This is both simplistic ignoring the complexities of individual circumstances, social contexts, poverty, of mental health conditions and addiction - and ethically questionable in the context of a liberal democracy.

The shift in prison ideology over the twentieth century can be in part attributed to a generalised shift in the conception of prisoners as objects to be managed, towards subjects with individual rights and potential. We would argue that a further shift is required, from subjects to citizens. Citizens have responsibilities, but they also have rights that extend beyond basic human rights and are broader than technical rights; to be valued and supported in a sophisticated manner according to individual needs and opportunities within the context of a welfare state. Such a shift means inappropriate security measures that obstruct a citizen's opportunities in the future could be a violation of these rights.

Whilst limited in scope and influence to engaging with current commissioning and design practices, the Wellbeing in Prison project sought to 'nudge' thinking further in this direction. ${ }^{63}$ By setting out wellbeing as a prime goal of prison design, the status of individuals is elevated beyond basic rights to the anticipation of a positive environment in which greater potential is enabled, rather than simplistically directed. ${ }^{64}$ The contention is that environmental psychology links stimuli from the environment to health and wellbeing, rather than promoting specific behaviours. Until recently, the application of environmental psychologybased techniques had been limited to prompting passivity, thereby reducing violence within prisons. ${ }^{65}$

At HMP Berwyn, a prison designed without any notable new architectural measures to promote wellbeing, the management team consulted with academic experts on what measures could be taken post-completion of the building. This resulted in the large-scale, high-quality images of landscape scenes that decorate the communal spaces. Tentative though these measures are, they indicate a positive aspiration as well as a strong critique of prison architecture. At HMP Berwyn there are long views of the Welsh countryside that could have literally met this psychological need if the buildings had been designed to take advantage of them. Inspirational images in prison are not a new measure; what is new is their basis in evidence, rather than the more traditional use as metaphors. ${ }^{66}$ 

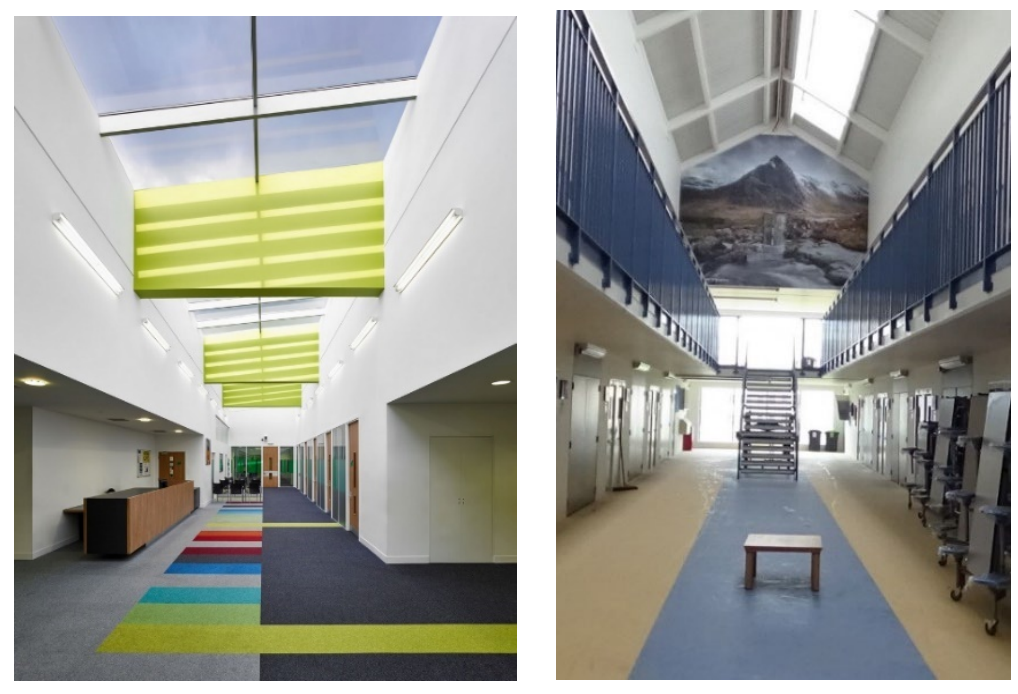

Fig. XI - Two approaches to psychology in prison design - left, architecture that combines natural daylight with views of the sky in HMP Low Moss and right, large-scale print of a landscape in HMP Berwyn. It should be noted that the functions of the two spaces are not the same. HMP Low Moss by Holmes Miller Architects, copyright Andrew Lee / Scottish Prison Service. HMP Berwyn copyright HMP Berwyn / HMPPS. All used with permission.

The aim of the Wellbeing in Prison project was not only to propose architectural measures, but to link them through evidence to potential outcomes, so they could be more firmly valued in the commissioning process. By requiring the architecture to fulfil a role in supporting health and wellbeing, for which there is more evidence than directly supporting rehabilitation, the case can be made for increasing resources.

A stronger case, however is that the chain of measures required to reduce reoffending, of which prison is only one part, must be complete along its whole length to be effective. ${ }^{67}$ Prison is a significant link in that chain and the design of prison is so frequently and evidently detrimental to its residents, visitors and workers that it could be said to be broken. ${ }^{68}$ The case for fixing this broken link is clear and the Wellbeing in Prison Design Guide provides practical steps towards resolving it.

Nonetheless, the report is clear that implementing all its recommendations will not result in a 'good' prison, but merely better conditions than currently exist. At the higher level in its hierarchy, the report recommends improvements to the processes of commissioning and design; including user-engagement in the briefing process as trialled in the fieldwork; and a quasi-independent design review to continually test the balance between security, costs and qualitative provision. There are good indications that this is taking hold, however the real test is to what extent this survives procurement. Earlier in this paper we discussed the related effects of PFI procurement on design and whilst it is not clear how new prisons will be procured, it is apparent that the choice of procurement influences outcomes. ${ }^{69}$ 


\section{Conclusions}

Prison remains an ethically contested topic, that appears to have been politically resolved in recent decades through an 'out of sight out of mind' philosophy; or warehousing as some have described it. In the context of dwindling public resources and a relentlessly increasing prison population, this political resolution now appears under threat, providing a strong impetus for a new approach. In the longer term, the financial case for change is clear, but politics is infamously poor at allocating investment for the longer term. A more fruitful approach may be the reconsideration of the status of those in prison as citizens in the contemporary sense of what this means for both rights and expectations. ${ }^{70}$ In a recent article for the RSA Journal, Karthaus argued more generally that the way we design our buildings has not yet transformed to meet these expectations and that society bears heavily the costs of this mismatch. ${ }^{71}$ Nonetheless, many new schools, libraries and hospitals are clearly designed with a generous attitude to the principles of supporting health and wellbeing, without the basis of explicit evidence and only limited user input. Gradually, the public understanding that poorly-designed buildings are a costly obstruction is taking hold; extending beyond pure functionality to qualities that are central to environmental psychology.

This is manifestly not the case in recent prison building, with only a couple of notable exceptions. HMP Low Moss in Scotland was visited as part of the Wellbeing project fieldwork and is argued to contain some of the best prison design measures in the UK. It appears to have been commissioned as a 'leap of faith' by the Scottish Prison Service; that if a prison is to be a place of public education, then its architecture should reflect that first. The report notes that the architecture is difficult to separate from other factors in the assessment of how successful a prison is in meeting its objectives, and perhaps for this reason it has not had the recognition it deserves. ${ }^{72}$

The ethical question of whether a 'good' prison model exists at all is considered a moot point in this paper. The most progressive and ambitious proposals for reform still mostly assume that incarceration is the only measure that can satisfy public demand for justice and punishment. ${ }^{73}$ Indeed, some have criticised internationally renowned examples of prison architecture as 'gilded cages.' A more provocative project called the Free Prisoner challenges this assumption, but in doing so merely serves to highlight the intransigence of the status quo. ${ }^{74}$ Meanwhile, the authors' position is that increased public and professional interaction with the commissioning, procurement, design, and operation of prisons is an urgent ethical, financial, and political necessity. During our work, we found that neighbouring communities to the prisons we worked with were more appreciative of the challenges and constraints placed on those leaving prison when they regularly encountered prisoners on day-release. ${ }^{75}$ This is anecdotal but was reinforced by others working in the sector. Decades of isolating prisons from communities is clearly a major factor in public attitudes and a barrier to reintegration into society.

The RSA Transitions project argued for locally-constituted networks, incorporating regional and national agencies, in a place-specific form as a practical means to bridge the gap between the social isolation of imprisonment and the need to engage with society for 
resettlement. The pilot project at HMP Humber demonstrated how an analysis of existing physical and organisational assets as well as limitations could be repurposed to provide this network. Architectural design thinking is fundamental to this, as the relationship between buildings, users and the wider community is the prime objective. To date and especially in recent decades, too little design thinking has been applied to prison, and both society and individuals are paying heavily as a result. Our overall goal in undertaking this work is to catalyse more design thinking to tackle this.

At the outset, the research work carried out by our practice Matter Architecture, was undertaken out of an interest in the fundamental relationship between people and the built environment; rather than a specific, commercial interest in prison architecture. The relatively extreme challenge of prison environments provides a unique opportunity to make the case for this relationship as an impetus for better design. The same logic, evidence and methodological approach applies to all building types, especially in hospitals, education facilities and shared housing such as co-living. As well as continuing to develop our research further in the prison sector, we are now exploring these wider applications.

\section{END}

[Total word count - 9376 excl. figure references, bibliography, notes and references] 


\section{Bibliography}

J. Bentham, Panoptican: or the Inspection House, (London: Dodo Press, 2008 ed)

S. Coates, Unlocking Potential: A Review of Education in Prison (London: Ministry of Justice, 2016)

Commission on English Prisons Today, Do Better Do Less: The Report of the Commission on English Prisons Today, (London: The Howard League for Penal Reform, 2010)

G.W. Evans, Environmental Stress (New York: Cambridge University Press, 1982)

M. Foucault, The Subject and Power (Critical Inquiry, Vol. 8:4,1982) pp.777-795

D. Halpern, Social Capital (Cambridge: Polity Press, 2005)

A. Haapakangas, R. Helenius, E. Keskinen and V. Hongisto, Perceived Acoustic Environment, Work Performance and Wellbeing Survey Results from Finnish Offices, in 9th International Congress on Noise as a Public Health Problem (ICBEN) 21-25 July 2008, Mashantucket, Connecticut, USA.

HM Chief Inspector of Prisons for England and Wales, Annual Report, 2016-17 (London: HMIP, 2017)

Home Office, Criminal Justice Act (London: TSO, 2003)

G. Garton Grimwood, Briefing paper - Building prisons in England and Wales: the bigger the better? (London: House of Commons Library, 2016)

D.C. Glass, and J.E. Singer, Urban Stress, (New York: Academic Press, 1972)

S. Griffiths, H. Kippin, H. and G. Stoker, Public Services: A New Reform Agenda (London: Bloomsbury, 2013)

Y.Jewkes, B.Crewe, and J.Bennett (Eds.), Handbook on Prisons; Second Edition (London: Routledge, 2016)

Y. Jewkes, and D. Moran, Prison Architecture and Design: Perspectives from Criminology and Carceral Geography in Oxford Handbook of Criminology (Oxford: Oxford University Press, 2017)

Y.Jewkes, E.Slee and D.Moran, The Visual Retreat of the Prison: Non-Places for Non-People, in M.Brown and E.Carrabine, eds. Routledge International Handbook of Visual Criminology (Abingdon: Routledge, 2017) pp.293-304

R. Karthaus, Life Plans; Applying Co-design to Architecture Can Create Buildings That Change with the Times and Improve Public Service Delivery, in RSA Journal Issue 1, 2017 (London: RSA, 2017) pp.40-43

R. Karthaus, L. Bernheimer, R. O'Brien, and R.P. Barnes, Wellbeing in Prison Design; A Design Guide (published online at: http://www.matterarchitecture.uk/research/, 2017)

K.Lenton, The Free Prisoner: From Removal to Inclusion (published online http://www.thejusticegap.com/2017/02/free-prisoner-removal-inclusion/, 2017)

K. Lockyer, Edited by M. Chambers, Future Prisons; A Radical Plan to Reform the Prison Estate (London: Policy Exchange, 2017) 
Lord Carter's Review of Prisons, Securing the Future - Proposals for the Efficient and Sustainable Use of Custody in England and Wales (London: Lord Carter's Review of Prisons, 2007)

T.A. Markus, Buildings and Power: Freedom and Control in the Origin of Modern Building Types (London: Routledge, 1993)

Ministry of Justice and NOMS, Prison Safety and Reform (London: Ministry of Justice, 2016)

R. O'Brien, R. Karthaus, and J. Marshall MBE, RSA Transitions; Building a Rehabilitation Culture (London: RSA, 2014)

P. Ormerod, Positive Linking: How Networks Can Revolutionise the World (London: Faber \& Faber, 2012)

Prison Reform Trust, The Woolf Report; A Summary of the Main Findings and Recommendations of the Inquiry into Prison Disturbances (London: Prison Reform Trust, 1991)

Prison Reforms Trust, Titan Prisons: A Gigantic Mistake (London: Prison Reform Trust, 2008)

H. Thurston, Y. Jewkes, R.Steer, J.Patience, K.Humphreys, M.Goldman and S.Mark, Rehabilitation by Design; Influencing Change in Prison Behaviour (London: Gleeds, 2016)

J. Vischer, Towards a User-Centred Theory of the Built Environment, in Building Research \& Information, Vol 36.3 (London: Routledge 2008) pp.231-240

R.E Wener, The Environmental Psychology of Prisons and Jails: Creating Humane Spaces in Secure Settings, (Cambridge: Cambridge University Press, 2012)

\section{Notes and References}

1 S. Griffiths, H. Kippin, H. and G. Stoker, Public Services: A New Reform Agenda (London: Bloomsbury, 2013)

2 See for example Storstorm Prison, Denmark; Halden Prison, Norway; Bastoy Prison, Norway and Leoben Prison, Austria

3 R. O'Brien, R. Karthaus, and J. Marshall MBE, RSA Transitions; Building a Rehabilitation Culture (London: RSA, 2014)

4 R. Karthaus, L. Bernheimer, R. O'Brien, and R.P. Barnes, Wellbeing in Prison Design; A Design Guide (published online at: http://www.matterarchitecture.uk/research/, 2017)

5 Ministry of Justice and NOMS, Prison Safety and Reform (London: Ministry of Justice, 2016)

6 Home Office, Criminal Justice Act (London: TSO, 2003) 
7 Commission on English Prisons Today, Do Better Do Less: The Report of the Commission on English Prisons Today, (London: The Howard League for Penal Reform, 2010)

8 See Michael Howard in the Times 7 December 2010 on the relationship between prison and crime numbers and Dalrymple T. New English Review, September 2009

9 R. O'Brien, R. Karthaus, and J. Marshall MBE, RSA Transitions; Building a Rehabilitation Culture (London: RSA, 2014) p.9

10 See https://www.gov.uk/government/organisations/ministry-of-justice/about/statistics for reoffending rates, staffing, prison population etc.

11 Y.Jewkes, B.Crewe, and J.Bennett (Eds.), Handbook on Prisons; Second Edition (London: Routledge, 2016)

12 J. Bentham, Panoptican: or the Inspection House, (London: Dodo Press, 2008 edition)

13 M. Foucault, The Subject and Power (Critical Inquiry, Vol. 8:4,1982) pp.777-795

14 T.A. Markus, Buildings and Power: Freedom and Control in the Origin of Modern Building Types (London: Routledge, 1993)

15 Y.Jewkes, E.Slee and D.Moran, The Visual Retreat of the Prison: Non-Places for NonPeople, in M.Brown and E.Carrabine (Eds.), Routledge International Handbook of Visual Criminology (Abingdon: Routledge, 2017) pp.293-304

16 Lord Carter's Review of Prisons, Securing the Future - Proposals for the efficient and sustainable use of custody in England and Wales (London: Lord Carter's Review of Prisons, 2007)

17 Ibid, p.5

18 See https://www.macegroup.com/media-centre/170413-ministry-of-justice-appoints-mace-toprison-estates-transformation-programme

19 See https://www.gov.uk/government/statistics/prison-population-figures-2018

20 See https://issuu.com/housingdotcom/docs/prison_housing

21 See https://www.thersa.org/action-and-research/rsa-projects/public-services-and-communitiesfolder/prison-learning-network

22 See https://theclinkcharity.org/

23 See https://www.thersa.org/globalassets/pdfs/reports/the-learning-prison-report.pdf

$24 \mathrm{Ibid}$

25 A term coined by sociologist Erving Goffman in 1961

26 See https://theconversation.com/how-to-build-better-prisons-55174

27 See https://www.thersa.org/globalassets/pdfs/reports/the-learning-prison-report.pdf 
R. O'Brien, R. Karthaus, and J. Marshall MBE, RSA Transitions; Building a Rehabilitation Culture (London: RSA, 2014)

D. Halpern, Social Capital (Cambridge: Polity Press, 2005)

30 R. O'Brien, R. Karthaus, and J. Marshall MBE, RSA Transitions; Building a Rehabilitation Culture (London: RSA, 2014) p.11

31 See https://theclinkcharity.org/

32 R. O'Brien, R. Karthaus, and J. Marshall MBE, RSA Transitions; Building a Rehabilitation Culture (London: RSA, 2014) p.29

33 HMP Humber (formerly HMP Everthorpe) was built in the 1950s as Borstal for male young offenders and the farmstead was built at the same time as the prison to provide purposeful and rehabilitative activity for the boys. This included a piggery and a planted woodland for the pigs to forage in. The farmstead is now largely disused. The site also contained 80-odd houses originally built for staff, but since mostly sold on to the public and a derelict Victorian manor house which had been in use as a staff mess facility in the past.

34 R. O'Brien, R. Karthaus, and J. Marshall MBE, RSA Transitions; Building a Rehabilitation Culture (London: RSA, 2014) p.12

35 Ibid, p.12

36 R. Karthaus, L. Bernheimer, R. O'Brien, and R.P. Barnes, Wellbeing in Prison Design; A Design Guide (published online at: http://www.matterarchitecture.uk/research/, 2017)

37 'Benefits' in Government procurement processes are required as outcomes of commissioning. In this case, the key outcome is a reduction in reoffending. The connection between the project being commissioned and the outcome is rarely simple or direct, making it difficult to evidence. The Wellbeing in Prison Design project sought to illustrate ways in which this connection could be strengthened. A further uncertainty is the weight given in cost terms to realising these benefits and this is not known by the authors.

38 S. Coates, Unlocking Potential: A Review of Education in Prison (London: Ministry of Justice, 2016) p.8

39 See https://assets.publishing.service.gov.uk/government/uploads/system/uploads/attachment_data/file/449357/research-analysis-offender-assessment-system.pdf

40 R. Karthaus, L. Bernheimer, R. O'Brien, and R.P. Barnes, Wellbeing in Prison Design; A Design Guide (published online at: http://www.matterarchitecture.uk/research/, 2017) p.91

${ }^{41}$ Ministry of Justice and NOMS, Prison Safety and Reform (London: Ministry of Justice, 2016) p.3

42 R. Karthaus, L. Bernheimer, R. O'Brien, and R.P. Barnes, Wellbeing in Prison Design; A Design Guide (published online at: http://www.matterarchitecture.uk/research/, 2017) p.19

43 D.C. Glass, and J.E. Singer, Urban Stress, (New York: Academic Press, 1972) and G.W. Evans, Environmental Stress (New York: Cambridge University Press, 1982) 
R. Karthaus, L. Bernheimer, R. O'Brien, and R.P. Barnes, Wellbeing in Prison Design; A Design Guide (published online at: http://www.matterarchitecture.uk/research/, 2017) p.22

45 Ibid, p.101

46 J. Vischer, Towards a User-Centred Theory of the Built Environment, in Building Research \& Information, Vol 36.3 (London: Routledge 2008) pp.231-240

47 R. Karthaus, L. Bernheimer, R. O'Brien, and R.P. Barnes, Wellbeing in Prison Design; A Design Guide (published online at: http://www.matterarchitecture.uk/research/, 2017) p.101

48 G. Garton Grimwood, Briefing paper - Building prisons in England and Wales: the bigger the better? (London: House of Commons Library, 2016)

49 It is worth noting that this publicly stated policy drew criticism from some newspapers, with the Daily Mail branding it 'Britain's cushiest prison.' See http://www.dailymail.co.uk/news/article3518316/The-cushiest-jail-Britain-Prisoners-phones-rooms-say-goodnight-children-warders-knockentering.html

50 R. Karthaus, L. Bernheimer, R. O'Brien, and R.P. Barnes, Wellbeing in Prison Design; A Design Guide (published online at: http://www.matterarchitecture.uk/research/, 2017) p.56

51 See https://www.wellcertified.com/

52 R. Karthaus, L. Bernheimer, R. O'Brien, and R.P. Barnes, Wellbeing in Prison Design; A Design Guide (published online at: http://www.matterarchitecture.uk/research/, 2017) p.134

53 Ibid, p.154

54 Ibid, p.188

55 See https://www.thersa.org/action-and-research/rsa-projects/public-services-and-communitiesfolder/new-futures-networks

56 RSA $6^{\text {th }}$ March 2018, author's notes including Minister's response to author's question.

57 During the period of these projects, the probation service was part-privatised under the programme Transforming Rehabilitation, ostensibly to reduce reoffending rates. The results to date have differed by area but overall found to be poor, with structural problems underlying the performance. http://www.russellwebster.com/tag/transforming-rehabilitation/

58 The UK Justice system is organised into risk categories; where $A$ is the highest risk to D lowest risk. The most accessible information is available on Wikipedia https://en.wikipedia.org/wiki/Prisoner_security_categories_in_the_United_Kingdom

59 Recent MoJ analysis found that Release on Temporary Licence (ROTL), where prisoners are allowed to take up work outside of prison during the day and return in the evening, had a measurable positive effect on reoffending. The use of ROTL has been significantly scaled back over the past few years in response to security concerns.

See https://assets.publishing.service.gov.uk/government/uploads/system/uploads/attachment_data/file/709123/rotl-report.pdf 
60 Sources vary - until recently the ONS stated the cost as $f 9.5 \mathrm{bn}$ - $f 13 \mathrm{bn}$ whereas the MoJ recently stated the cost as $f 15$ billion per annum. Any of these figures are likely to underestimate the true cost to wider society.

61 Numbers of absconds and non-returns from leave are higher, but still statistically very small. See https://assets.publishing.service.gov.uk/government/uploads/system/uploads/attachment_data/file/553298/noms-digest-report-2015-2016.pdf

62 This is patently not a simple calculation, but the orders of magnitude difference are huge and so we shift here to the moral equation.

63 It should be noted that the objective of providing for rehabilitation in the current prison procurement programme is an explicit objective and is clearly challenging long-held assumptions in prison design in a progressive direction. The extent to which this will be realised in the completed new prisons has yet to be seen.

64 An important note here is that the guidance was aimed at improving the environment for all users of the prison, including staff and visitors whose needs are often overlooked or undervalued.

65 R.E Wener, The Environmental Psychology of Prisons and Jails: Creating Humane Spaces in Secure Settings (Cambridge: Cambridge University Press, 2012)

66 Metaphorical images of improvement, such as 'bonding hands' are also used in HMP Berwyn

67 This chain is explored at length through a range of frameworks and perspectives across both the projects described in this paper.

68 See https://howardleague.org/why-the-system-is-broken/

69 The relationship between procurement and design outcomes has been much debated and is currently the subject of an RIBA / RICS / CIOB initiative for improving quality in construction. See https://www.architecture.com/knowledge-and-resources/knowledge-landing-page/riba-leadsconstruction-industry-initiative-to-improve-building-quality

70 A key ethical point in this particular debate is whether prisoners should have the vote. The European Council on Human Rights asserts that voting is in fact a human right and has been challenging the UK on its position of banning prisoners from voting, which was settled in a compromise by the Government allowing a small number (around 100) of low-risk prisoners to vote in 2017.

71 R. Karthaus, Life Plans; Applying co-design to architecture can create buildings that change with the times and improve public service delivery, in RSA Journal Issue 1, 2017 (London: RSA, 2017) pp.4043

72 Scotland has devolved powers over its prison service and so Scottish prisons are not included in HMPPS prison ratings for England and Wales.

73 'Category D' or 'open prisons' do operate in the UK but are characterised by being generally remote from urban centres and communities. Electronic tagging is also used for some offenders.

74 K.Lenton, (2017) The Free Prisoner: From Removal to Inclusion (published online http://www.thejusticegap.com/2017/02/free-prisoner-removal-inclusion/) 
75 Since 2010, Release on Temporary Licence (ROTL) has been significantly reduced. On $24^{\text {th }}$ May 2018 on Radio 4, the Justice Secretary David Gauke said this had to change, something welcomed widely by Justice commentators. It is apparent, however that prison design currently does not fully facilitate a major increase in $\mathrm{ROTL}$, another area requiring design attention. 